\title{
EL MOCHILERO: JOGO DIGITAL EDUCACIONAL PARA O DESENVOLVIMENTO DA COMPETÊNCIA INTERCULTURAL DE APRENDIZES DE LÍNGUA ESPANHOLA
}

\author{
Daiane Padula Paz - IFRS Porto Alegre - daippaz@gmail.com \\ Humberto Jorge de Moura Costa - IFRS Veranópolis - humberto@humbertomoura.com.br \\ Márcia Häfele Islabão Franco - IFRS Porto Alegre - marcia.franco@poa.ifrs.edu.br \\ Silvia de Castro Bertagnolli - IFRS Porto Alegre - silvia.bertagnolli@poa.ifrs.edu.br
}

Resumo: Considerando-se as potencialidades dos jogos digitais educacionais e a necessidade de um recurso diferenciado para o desenvolvimento da competência intercultural de aprendizes de língua espanhola, este artigo descreve a pesquisa que origina o produto jogo digital educacional El Mochilero, como proposta de recurso para um ensino interativo, lúdico e motivador. Descreve os procedimentos de desenvolvimento e de avaliação do jogo, bem como do projeto pedagógico "Cultura en la Mochila" elaborado paralelamente como proposta que alia Informática na educação e ensino híbrido. Os resultados demonstram que jogo digital e o projeto integrado foram considerados exitosos para seus fins atingindo os objetivos previstos.

Palavras-chave: jogos digitais educacionais; competência intercultural; língua espanhola.

\section{EL MOCHILERO: EDUCATIONAL DIGITAL GAME FOR DEVELOPMENT OF THE INTERCULTURAL COMPETENCE OF SPANISH-SPEAKING LEARNERS}

Abstract: Considering the potential of digital educational games and the need for a differentiated resource for the development of the intercultural competence of Spanishspeaking learners, this research proposes the educational digital game El Mochilero, for interactive, ludic and motivational teaching. It also describes the pedagogical project "Cultura en la Mochila", which links computing in education in a proposal of hybrid teaching combined with meaningful learning. It presents the evaluation procedures of the game and the project, in addition to the results obtained, which denote that the software and the proposal were considered successful for its purposes achieving the proposed objectives.

Keywords: educational digital games; intercultural competence; spanish language.

\section{INTRODUÇÃO}

Com a expansão da Informática na Educação muitas coisas mudaram no processo de ensino e aprendizagem, entre elas a abordagem e a disponibilidade de recursos diversificados. Nos últimos anos aumentou, de maneira exponencial, a disponibilidade de jogos digitais educacionais; conhecidos também como jogos sérios, os quais têm sido utilizados como importante ferramenta no processo de aquisição do conhecimento, servindo como estratégia de aprendizagem nas mais diversas áreas e níveis de ensino, especialmente por envolverem diversos fatores positivos, cognitivos, culturais, sociais e afetivos (Mattar, 2010).

Por outro lado, com relação ao ensino de idiomas, também houve mudanças de perspectivas. Atualmente, entende-se que ao aprender uma língua estrangeira é essencial conhecer também aspectos socioculturais dos países que a possuem como oficial, para desenvolver, além das habilidades básicas, a competência intercultural. Considerando-se 
as potencialidades dos jogos sérios e a necessidade de um recurso diferenciado para o desenvolvimento da competência intercultural de aprendizes de língua espanhola (LE), esta pesquisa apresenta o Jogo Digital Educacional (JDE) El Mochilero, desenvolvido a partir de importantes referências da área, como proposta para um ensino interativo, lúdico e motivador. Apresenta também, de forma descritiva, os procedimentos realizados ao longo da pesquisa, como fases de desenvolvimento do JDE, validação, dados relevantes e discussão de resultados.

Contudo, a relevância acadêmica deste estudo se constitui não apenas por considerar o emergente fenômeno de JDEs e seus possíveis benefícios, mas também por apresentar uma proposta diferenciada para o ensino de aspectos ainda pouco evidenciados nas aulas de línguas, mas que são essenciais para o desenvolvimento pleno do aprendiz: sua competência intercultural. Em última instância, propõe um recurso atual integrado a um projeto pedagógico, desenvolvido sob uma linha construtivista, que incorpora Informática na Educação em uma proposta híbrida de ensino para a disseminação de aspectos socioculturais de países hispano falantes.

\section{CONTEXTO, MATERIAIS E MÉTODOS}

Esta pesquisa parte da hipótese de que o uso de jogos educacionais pode proporcionar motivação ao estudante e ser eficaz no ensino; considera também, o valor da dimensão cultural para aprendizes de LE. A iniciativa deu-se por perceber que há pouca disponibilidade de JDE em LE e, menos ainda, com enfoque em aspectos socioculturais.

Para tanto, fez-se necessário realizar diversos procedimentos que definem a metodologia desta pesquisa, começando por uma refinada pesquisa bibliográfica sobre as temáticas envolvidas e teorias relacionadas ao uso de jogos, como a da Aprendizagem significativa, de David Ausubel (2003), Aprendizagem baseada em jogos digitais, de Marc Prensky (2012), Ensino híbrido (Bacich et al., 2015), as quais compõem o referencial teórico. Logo, pesquisou-se sobre características e tipologia de JDs e buscou-se conhecer o estado da arte de jogos com enfoque intercultural, ratificando-se então uma lacuna na área. Na sequência foram estudados documentos norteadores - Plano Curricular do Instituto Cervantes (PCIC) e Marco Comum Europeu de Referência (MCER) - para o desenvolvimento da referida competência em LE, os quais serviram de base para a produção do software educacional El Mochilero.

Ainda, foram estudados os procedimentos de desenvolvimento de JDs, abrangendo os períodos de pré-produção, produção e pós-produção, de modo que o produto fosse bem elaborado e que houvesse registros formais desde a fase de prototipagem até a etapa de divulgação. Na etapa de pré-produção do jogo percebeu-se a necessidade de elaborar uma proposta integradora que envolva os conceitos teóricos de aprendizagem significativa, ensino híbrido e competência intercultural, que embasam esta pesquisa, para aplicação prática em sala de aula. Dessa forma, foi desenvolvido o projeto de ensino híbrido "Cultura en la Mochila", cujo nome faz referência ao conteúdo principal da pesquisa e ao jogo que finaliza o projeto.

Com o propósito de validar e averiguar as contribuições do jogo El Mochilero, fez-se necessário buscar na literatura recente, modelos de avaliação de jogos, para então selecionar o mais adequado, considerando dois importantes aspectos: i) avaliação do jogo considerando suas características como design, jogabilidade e experiência do 
usuário; ii) avaliação do aprendizado referente aos objetivos da proposta (desenvolvimento da competência intercultural). Assim, para esta avaliação optou-se pelo modelo MEEGA+ (Savi, 2011) por considerá-lo bastante abrangente.

Esta etapa realizou-se então, sob duas perspectivas: a primeira, a partir de um questionário estruturado, da versão adaptada do modelo MEEGA+; a segunda, a partir do levantamento de dados de desempenho (pontuação) dos estudantes em cada rodada. Cabe ressaltar que se observou também o interesse e engajamento destes em relação ao jogo. Os resultados foram mensurados e descritos para análise e discussão.

Em suma, esta pesquisa se desenvolve em diversas etapas, muitas destas realizadas simultaneamente, a saber: composição da fundamentação teórica; definição de diretrizes; desenvolvimento do software, elaboração e aplicação do projeto de ensino híbrido; aplicação e avaliação do JD; avaliação do projeto com sujeitos envolvidos; e, por fim, compilação e análise de dados coletados. Todos os procedimentos foram devidamente registrados, compondo as diversas seções desta pesquisa e importante material de referência.

Cabe destacar que este estudo, com enfoque de implementação de Informática na Educação, detém-se em teorias que se relacionam a esta área de conhecimento. Para tanto, delimitou-se temas de referência para o embasamento desta proposta de cunho pedagógico e, sobretudo, para uma orientação pautada em temas relevantes e atuais.

\section{JOGOS E APRENDIZAGEM}

Quando elaborados para fins educacionais, os jogos podem ser denominados como jogos educacionais ou educativos, jogos de aprendizagem ou jogos sérios (Savi, 2008). Embora haja discussões quanto a definição de jogo educacional, o que é certo é que podem ser definidos como educacionais quando são motivadores do processo de aprendizagem (Tarouco, 2004). Estes podem apresentar muitas vantagens, como: o desenvolvimento de habilidades cognitivas (Gros, 2006); melhorar a capacidade de trabalho em grupo (Mattar, 2010), permitem o reconhecimento e entendimento de regras (Tarouco, 2004) além de contribuir positivamente na aprendizagem (Wangenheim et al., 2009).

A partir da utilização de jogos educacionais, pode-se promover a Aprendizagem Baseada em Jogos Digitais (Battistela, 2016), defendida por Prensky (2012) ao afirmar que esta abordagem funciona por promover um envolvimento e um processo interativo da aprendizagem. Considerando tais aspectos agregados às linhas teóricas que abordam metodologias ativas e o ensino híbrido (Horn e Staker, 2015) optou-se por considerar o valor que esta proposta pode significar em estudos da área. Colaborando, nesta perspectiva, considerou-se também a teoria da Aprendizagem Significativa de David Ausubel que integra conceitos de subsunçores, materiais significativos e postura do aprendiz rumo a uma aprendizagem com significado.

\section{COMPETÊNCIA INTERCULTURAL}

O eixo central desta pesquisa está no desenvolvimento da competência intercultural. Dessa forma, definem-se conceitos de cultura, bem como suas relações intrínsecas, uma vez que língua e cultura andam juntas no processo de aprendizagem (Bravo-García, 2015). Detalha-se, ainda, as três seções da dimensão cultural descritas no PCIC (2006), e apoiadas no MCER (2002), essenciais para este estudo: os Referentes 
culturais, os Saberes e comportamentos e socioculturais e as Habilidades e atitudes interculturais.

Sob esta perspectiva, definem-se critérios para a elaboração das questões que compõem o Quiz do software El Mochilero, em uma proposta unificada e fundamentada nestes que são denominados os mais importantes documentos que norteiam o ensino de LE, culminando em uma proposta aplicável em diferentes contextos para a disseminação de aspectos socioculturais de países hispano falantes.

\section{PROJETO CULTURA EN LA MOCHILA}

Com a introdução de tecnologias digitais em sala de aula e a alternância de estratégias de ensino, desenvolveu-se, de forma mais ampla, o ensino híbrido (Bacich et al., 2015) que coloca o aluno em foco no processo de ensino, visando promover uma aprendizagem mais ativa e autônoma. Visando contextualizar a temática do jogo e conceitos de importantes linhas teóricas que abordam o ensino híbrido e a aprendizagem significativa, elaborou-se o projeto Cultura en la mochila, o qual propõe uma série de atividades integradas ao ensino de cultura hispânica às tecnologias.

O projeto baseia-se no modelo de sala de aula invertida e consiste na pesquisa de dados específicos sobre os países hispanofalantes. Aplicado em duas turmas do Ensino Médio de uma instituição pública durante um bimestre, serviu de incentivo e contexto para a aplicação do JD El Mochilero como proposta paralela, integrada a esta pesquisa mas não de caráter obrigatório de aplicação.

Para avaliação da proposta, além da observação constante da evolução e engajamento dos estudantes envolvidos, realizou-se a técnica de grupo focal, que através de perguntas disparadoras permitiu a coleta de dados. As informações obtidas indicaram a prática pedagógica efetivada como plenamente positiva. Triangulando os pontos observados, com depoimentos e registros dos estudantes, percebe-se que fazer um projeto desse teor possibilita novas formas de ensino e aprendizagem e favorece a motivação discente. Espera-se, nesse sentido, que a proposta contribua para animar docentes de línguas a promover práticas inovadoras.

\section{JOGO DIGITAL EDUCACIONAL EL MOCHILERO}

O jogo El Mochilero está desenhado como ferramenta complementar para o desenvolvimento da competência intercultural de aprendizes de LE, sob uma perspectiva de ensino e aprendizagem de valores, habilidades, atitudes e conhecimentos essenciais para despertar uma consciência de identificação étnica e respeito à multiculturalidade. Para tanto, o software proposto baseia-se em dois importantes documentos que norteiam o ensino do espanhol no mundo, já mencionados: o PCIC (2006) e o MCER (2002).

Cabe destacar que este JD não tem por finalidade o ensino de conteúdos gramaticais, nem o desenvolvimento de habilidades específicas que promovam fluência no idioma, entretanto, está desenvolvido totalmente em espanhol pelos seguintes motivos: i) há uma mínima oferta de jogos em língua espanhola, ii) a integração do idioma com a temática cultural torna a proposta mais coerente; iii) poderá proporcionar, mesmo de forma indireta, novos conhecimentos na língua meta.

Para o desenvolvimento de um jogo é preciso pensar três etapas principais: préprodução, produção e pós-produção (Mattar, 2010). Na primeira etapa, realizou-se a 
conceituação, o game design document e o planejamento de produção e arte; na segunda, o protótipo e a implementação; e na terceira etapa, foram realizados testes, disponibilização e divulgação do jogo e plano de arquivamento. Todas as etapas foram registradas, compondo relevante seção da pesquisa, sobretudo, para servir como fonte de consulta para a elaboração de versões posteriores do software.

O jogo apresenta um personagem viajante - El Mochilero - que está conhecendo países hispanofalantes e necessita conseguir moedas para prosseguir sua viagem, portanto o jogador deverá ajudá-lo respondendo às questões do quiz em cada uma das quatro fases, elaboradas a partir das seções: Referentes culturais, Saberes e comportamentos socioculturais e Habilidades e atitudes interculturais, as quais dão nome às fases 1 e 3 do jogo. Ainda, foi acrescentada uma quarta fase, denominada "Mito o verdad", a qual, com uma estrutura diferente faz uma revisão sobre os aspectos das fases anteriores.

A cada acerto o jogador recebe 100 (cem) pontos e avança para a questão seguinte. Esperando obter um desempenho satisfatório, a fase seguinte só será desbloqueada ao acertar, no mínimo, $50 \%$ das questões do quiz (Figura 1). Com finalidade de aprendizado, o usuário poderá retomar o jogo quantas vezes quiser e sempre será salvo seu maior desempenho no placar final de cada fase.
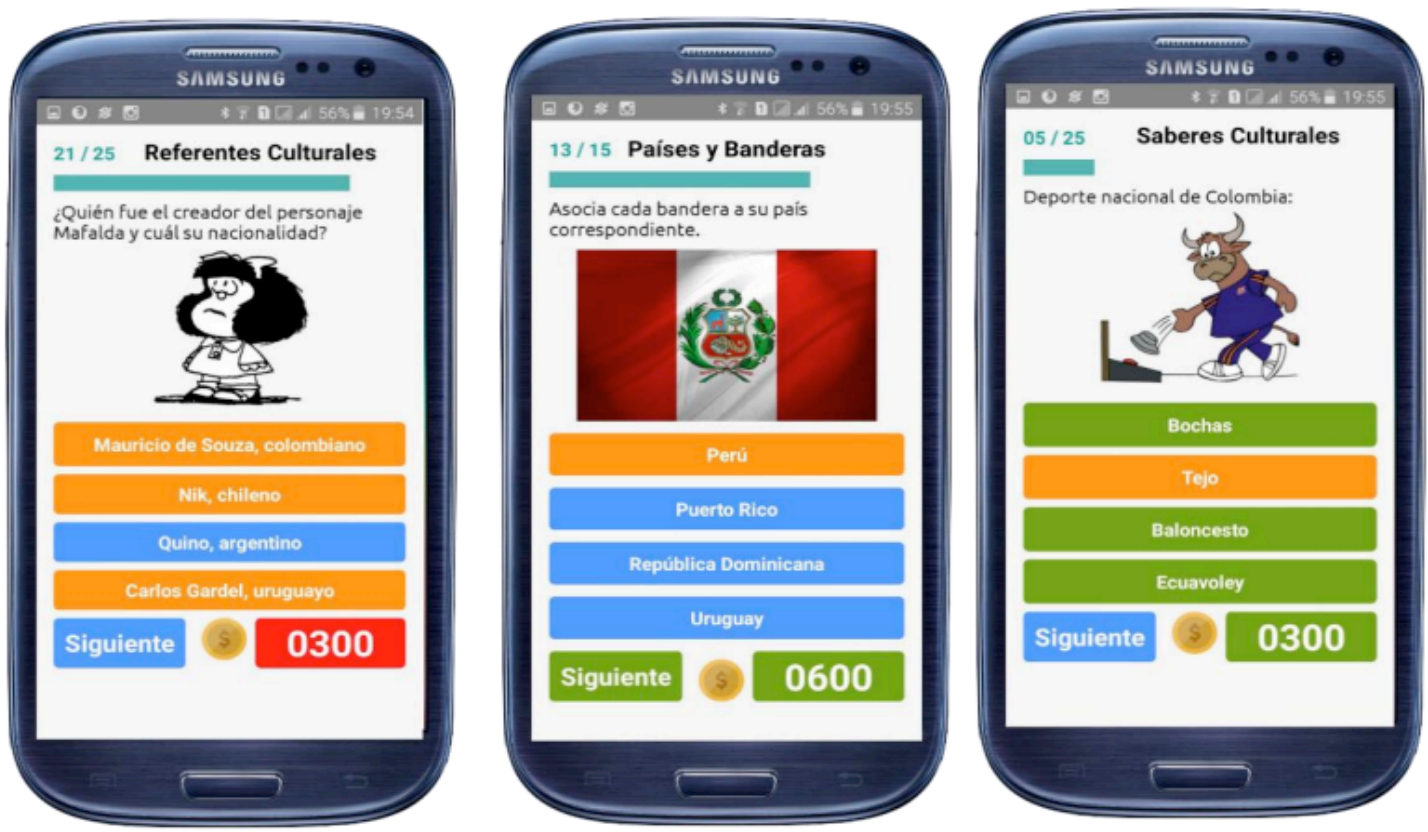

Figura 1: Telas do jogo

Para facilitar a difusão e o download do jogo optou-se por disponibilizá-lo, de forma gratuita, na loja de aplicativos Google Play, na categoria de apps de Educação. Espera-se, dessa forma, que estudantes, ao pesquisarem por aplicativos relacionados a cultura hispânica, encontrem o El Mochilero como uma opção de aprendizado e possam avaliá-lo. 


\section{RESULTADOS}

Qualquer tipo de procedimento sério de avaliação implica em coleta de dados. Estes precisam ser organizados, analisados, interpretados e comunicados adequadamente (Savi, 2011). Muitos dados foram obtidos a partir do Questionário de Avaliação do jogo e da Avaliação de Desempenho.

\subsection{RESULTADOS DO QUESTIONÁRIO DE AVALIAÇÃO DO JOGO}

Para que sejam considerados jogos educacionais, é preciso que estes tenham objetivos de aprendizagem bem definidos e ensinem conteúdos aos usuários, ou então, que promovam o desenvolvimento de estratégias ou habilidades para ampliar a capacidade cognitiva e intelectual dos alunos (Gros, 2003). Nos últimos anos, muitos jogos digitais têm sido desenvolvidos para colaborar no processo de ensino e aprendizagem, entretanto, é necessário que sua(s) funcionalidade(s) e eficácia sejam avaliadas de forma satisfatória.

Aplicado em duas turmas de Ensino Médio, o Questionário foi respondido por um total de 46 usuários. Para análise dos resultados considerou-se os itens de cada um dos blocos do questionário sendo, respectivamente: dados demográficos, experiência do jogador, estrutura do jogo, percepção da aprendizagem, competência intercultural e comentários. Diversos dados de grande importância foram obtidos através deste questionário, entretanto, neste artigo, apresentam-se apenas dados gerais com enfoque na experiência do jogador, sua percepção sobre a aprendizagem e ao desenvolvimento da competência intercultural.

A seção "Experiência do jogador" contém um total de 30 questões referentes à usabilidade, confiança, desafio, satisfação, interação, diversão, atenção e relevância. Considerando-se os resultados obtidos nessa seção, percebe-se que a ampla maioria avaliou como positiva sua experiência, em todos os aspectos, destacados pelo percentual de aceitação (Figura 2).

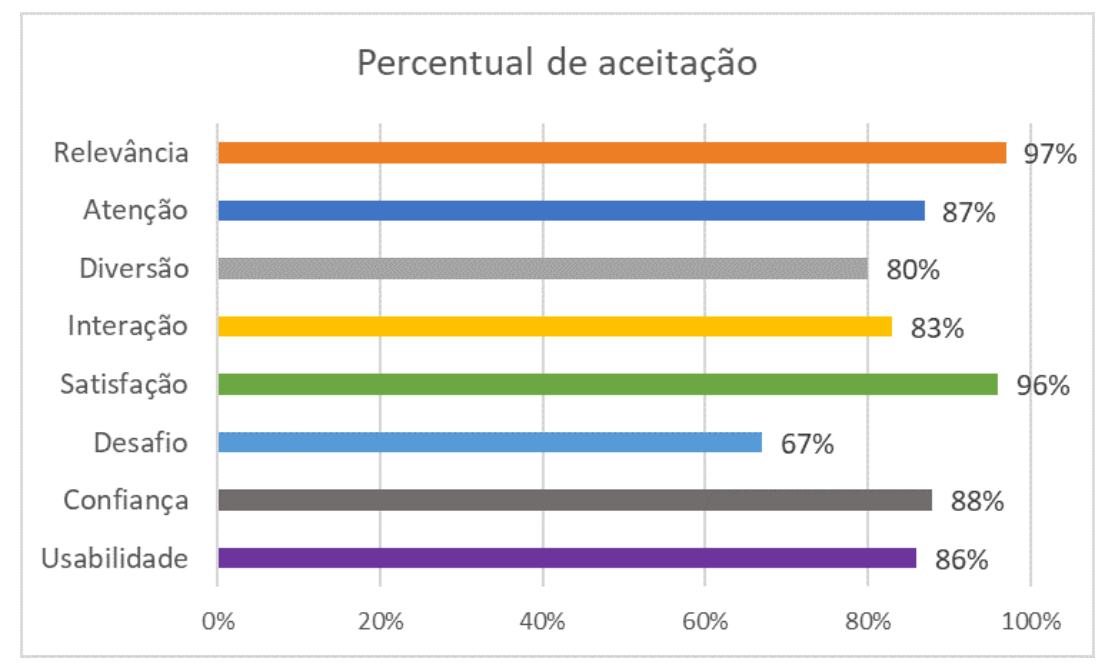

Figura 2: Percentual de aceitação Experiência do jogador

$\mathrm{Na}$ categoria desafio houve significativa indicação de que o jogo se torna monótono nas etapas. Possivelmente, essa afirmativa deve-se ao fato do jogo ser um 
protótipo de aplicativo, com um banco de questões ainda limitado. Destaca-se que a codificação do jogo foi concebida para suportar o acréscimo de novas perguntas e fases bastando inseri-las no banco de questões e que esta melhoria já está sendo elaborada para uma nova versão.

$\mathrm{Na}$ categoria interação, constatou-se que houve incidência de estudantes que indicaram que o jogo não proporciona interação entre os jogadores pois em sua percepção, interação se dá através da modalidade multiplayer. Embora haja um ranking automático elaborado pelo Google Play Games que está integrado no jogo, é fato que a interação com outros usuários pode ser melhor explorada e nesse sentido, espera-se implementar a opção desafio para que o usuário convide alguém para jogar, ou mesmo pela opção oponente aleatório.

A seção "Percepção da aprendizagem", composta por doze questões que buscam coletar dados sobre as contribuições do jogo El Mochilero como recurso educacional e para fins específicos dos objetivos planejados. Percebe-se que, há uma concordância forte, entre os participantes da pesquisa (Figura 3) nos mais diversos aspectos, que convergem à indicação deste software como positivo e importante para o ensino de aspectos de cultura hispânica e, por conseguinte, desenvolvimento da competência sociocultural dos usuários.

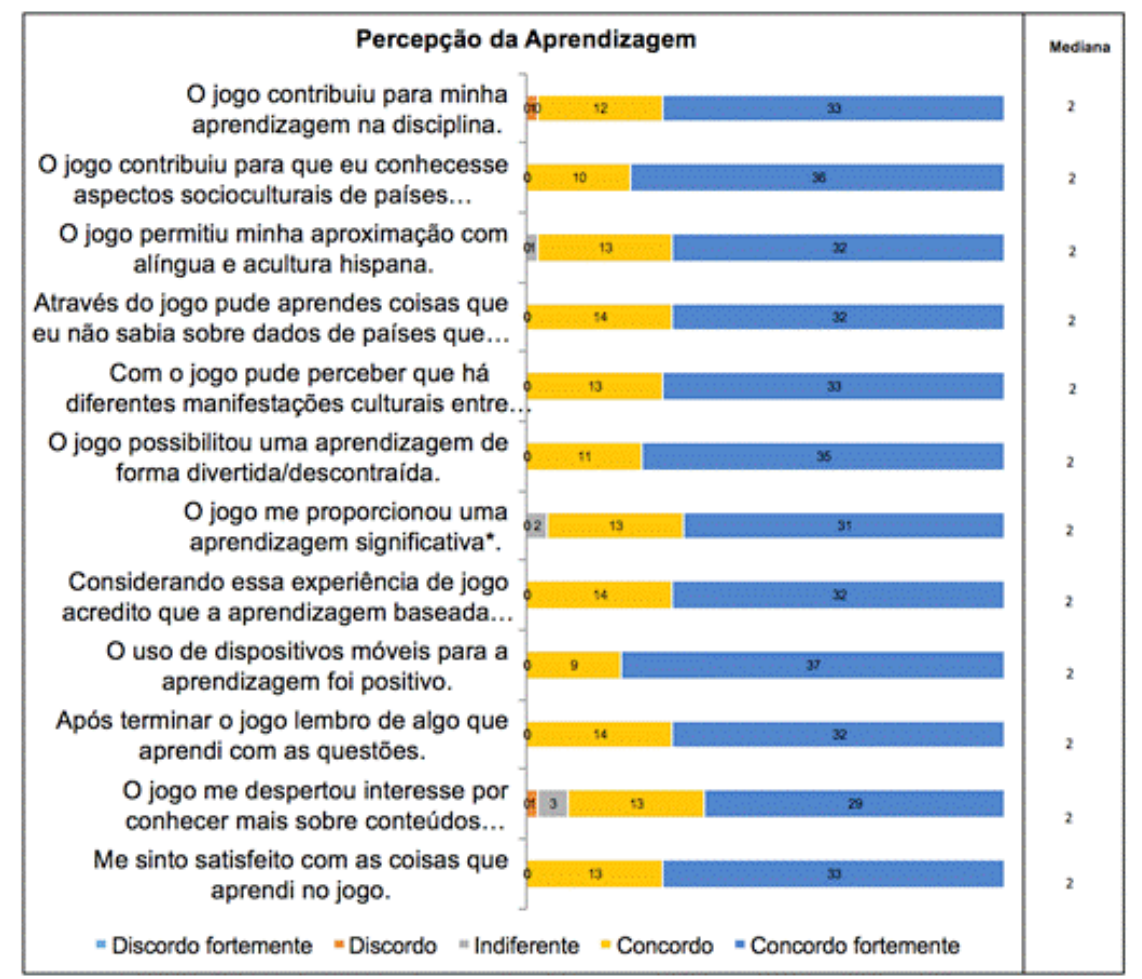

Figura 3: Dados Percepção da aprendizagem

$\mathrm{Na}$ seção "Competência intercultural" (Figura 4), percebe-se a ampla concordância de que o jogo colabora com o desenvolvimento da competência intercultural, fato de extrema relevância para os resultados desse trabalho. Considerando o conjunto de resultados dessa categoria e da categoria de percepção da aprendizagem, pode-se afirmar que houve êxito na proposta de implementação de um jogo digital 
educacional para o desenvolvimento da competência intercultural e que, nestas condições, o jogo elaborado atende a maioria dos quesitos de forma totalmente satisfatória, resultando ser uma significante e inovadora alternativa para esse fim.

Para visualização global dos resultados, além dos gráficos gerados pelo sistema MEEGA+, realizou-se o índice do percentual de aceitação geral de cada uma das quatro seções, tendo $85 \%$ de aceitação na seção experiência do jogador, $70 \%$ da estrutura do jogo, 99\% da percepção da aprendizagem e 93\% da competência intercultural. Os resultados globais confirmam um alto percentual de aceitação na totalidade, representando quase unanimidade de opinião entre os usuários do jogo.

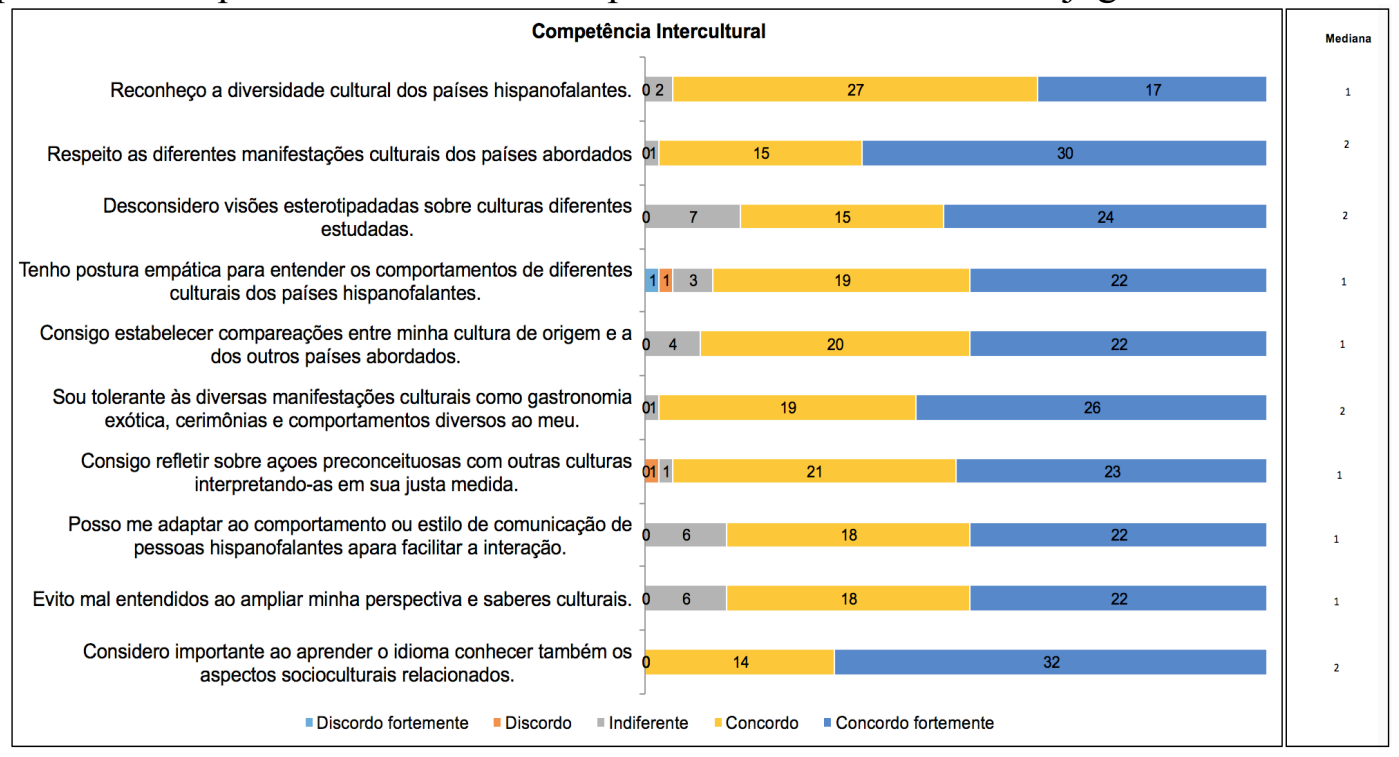

Figura 4: Dados Competência Intercultural

\subsection{AVALIAÇÃO DE DESEMPENHO}

O outro viés da avaliação foi realizado através da Avaliação de Desempenho dos jogadores, com o objetivo de verificar se, a cada jogada, seriam capazes de obter melhores rendimentos, dados estes auferidos pela pontuação final (acertos) em cada fase. Para tanto, foram realizadas, em sala de aula, quatro rodadas incluindo todas as fases do jogo. Para realizar a análise comparativa deve-se considerar que as fases 1 e 3 , denominadas Referentes Culturales e Saberes Culturales respectivamente, possuem um total de 25 questões (amostra) de 50 possíveis (população), enquanto na fase 2, denominada Países y banderas, totaliza 15 questões, de 21 possíveis. Na última fase, ¿mito o verdad?, são sorteadas 15 questões, de 30 possíveis.

Para compilação dos dados coletados foi utilizada uma análise de estatística descritiva, considerando as variáveis quantitativas de número de acertos de questões (Tabelas 1, 2, 3 e 4). Também foram utilizados, neste estudo, algumas medidas de tendência central, como a moda, mediana e a média aritmética. Efetuada por 43 participantes de duas turmas do ensino Médio, a avaliação de desempenho demonstrou que houve incremento da média aritmética, corroborado com o aumento da frequência de acertos indicados pela moda, indicando que, em todas as quatro fases do jogo, a maioria dos usuários evoluíram em desempenho. Este fato denota que, possivelmente, ao jogar de forma recorrente, as informações são retidas, gerando conhecimento sobre 
os aspectos abordados. Essa pesquisa não pretende avaliar a forma do aprendizado, mas compreende que, pela exposição ao lúdico, a motivação e a interação se fazem presentes.

Tabela 1. Desempenho por rodadas fase 1.

\begin{tabular}{|c|c|c|c|c|}
\hline & Rod. 1 & Rod. 2 & Rod. 3 & Rod. 4 \\
\hline Média & 12,77 & 14,93 & 15,49 & 17,05 \\
\hline Mediana & 12,00 & 15,00 & 15,00 & 17,00 \\
\hline Desvio & 2,56 & 3,71 & 3,74 & 4,13 \\
\hline Moda & 12,00 & 13,00 & 14,00 & 16,00 \\
\hline
\end{tabular}

Fonte: Elaborada pela autora.

Tabela 3. Desempenho por rodadas fase 3.

\begin{tabular}{|c|c|c|c|c|}
\hline & Rod. 1 & Rod. 2 & Rod. 3 & Rod. 4 \\
\hline Média & 13,58 & 14,21 & 15,35 & 16,23 \\
\hline Mediana & 13,00 & 14,00 & 15,00 & 16,00 \\
\hline Desvio & 3,10 & 3,43 & 3,93 & 4,17 \\
\hline Moda & 13,00 & 12,00 & 13,00 & 15,00 \\
\hline
\end{tabular}

Fonte: Elaborada pela autora.
Tabela 2. Desempenho por rodadas fase 2.

\begin{tabular}{|c|c|c|c|c|}
\hline & Rod. 1 & Rod. 2 & Rod. 3 & Rod. 4 \\
\hline Média & 10,77 & 11,28 & 11,42 & 12,33 \\
\hline Mediana & 11,00 & 11,00 & 12,00 & 13,00 \\
\hline Desvio & 2,63 & 2,99 & 3,23 & 2,74 \\
\hline Moda & 13,00 & 13,00 & 15,00 & 15,00 \\
\hline
\end{tabular}

Fonte: Elaborada pela autora.

Tabela 4. Desempenho por rodadas fase 4.

\begin{tabular}{|c|c|c|c|c|}
\hline & Rod. 1 & Rod. 2 & Rod. 3 & Rod. 4 \\
\hline Média & 10,28 & 11,40 & 12,84 & 12,74 \\
\hline Mediana & 10,00 & 11,00 & 13,00 & 13,00 \\
\hline Desvio & 2,36 & 2,36 & 1,86 & 2,20 \\
\hline Moda & 13,00 & 10,00 & 12,00 & 15,00 \\
\hline
\end{tabular}

Fonte: Elaborada pela autora.

\subsection{DISCUSSÃO}

Considerando a totalidade dos resultados obtidos tanto no Questionário de avaliação do JD quanto na Avaliação de Desempenho dos estudantes, é notório que os objetivos foram alcançados: o jogo foi bem aceito, mostrou-se como uma ferramenta válida para o desenvolvimento da competência intercultural e os estudantes obtiveram um crescente rendimento. Sob essa perspectiva e contexto, é possível afirmar que a este recurso mostra-se como importante estratégia para o ensino, validando totalmente a proposta do software El Mochilero.

Levando-se em consideração a consistência desta proposta, estão sendo realizadas algumas ações de aprimoramento do jogo a partir de indicações dos jogadores participantes da pesquisa e percepções dos desenvolvedores, tais como: ampliação do banco de questões, implementação de novas fases e/ou categorias, melhorias de design e usabilidade, integração com redes sociais, ampliação do sistema de pontuação, premiação, badges e ranqueamento.

\section{CONCLUSÃO}

Este artigo apresentou a proposta de um jogo digital educacional, El Mochilero, elaborado com a finalidade de desenvolver a competência intercultural de aprendizes de língua espanhola e disseminação de aspectos socioculturais de países hispano falantes. Para tanto, apresenta a importância dos jogos sérios na atualidade bem como teorias relacionadas à aprendizagem significativa, aprendizagem baseada em jogos digitais e ensino híbrido, que compõem referencial teórico dessa pesquisa.

Apresenta também o estado da arte, procedimentos de avaliação do jogo desenvolvido e alguns dos resultados obtidos neste amplo estudo, que considerou como positivo o uso do jogo como prática pedagógica, sobretudo aliado ao projeto Cultura em la Mochila que se revela como proposta inovadora de interação e de estímulo à construção do conhecimento de forma cooperativa, híbrida e atualizada. 
Esta pesquisa contribui não apenas pelo desenvolvimento de um software educacional, mas também pela tentativa de romper os moldes de ensino tradicional de idiomas, cooperando para a não restrição do ensino de habilidades linguísticas e cedendo espaço ao entendimento que a dimensão cultural ocupa no mundo. Todo este estudo motiva-se, sobretudo, pela incorporação efetiva e eficaz da Informática na Educação em ações experienciais exitosas que vinculem conteúdos a saberes, em práticas pedagógicas inovadoras, garantia de êxito no processo de ensino $\mathrm{e}$ aprendizagem da atualidade.

\section{REFERÊNCIAS}

Ausubel, D. P (2003) Aquisição e Retenção do Conhecimento: Uma perspectiva cognitiva. Trad. Lígia Teopisto. Lisboa: Plátano.

Bacich, L.; Neto, A., Trevisani, F. M. (2015) Ensino híbrido: personalização e tecnologia na educação. Penso Editora.

Battistella, P. (2016) ENgAGED: Um processo de desenvolvimento de jogos para ensino em computação. Tese. PPGCC, UFSC.

Bravo-García, E. (2015) América en la clase de español: del contenido cultural al psycofact. In: MarcoELE, Madrid, n.21, 2015.

Cervantes, Instituto (2006) "Plan Curricular del Instituto Cervantes”. Madri.

Consejo de Europa. (2002) "Marco común europeo de referencia para las lenguas": aprendizaje, enseñanza, evaluación. Madrid.

Gros, B. (2003). The impact of digital games in education. First Monday, v.8, n.7.

Gros, B. (2006). Juegos Digitales para comprender los sistemas complejos.In: Grup F9: Videojocs a l'Aula Revista Comunicación y Pedagogía, n.216.

Horn, M.; Steaker, H. (2015). Blended: usando a inovação disruptiva para aprimorar a educação. Porto Alegre: Penso.

Mattar, J.(2010) Games em educação: como os nativos digitais aprendem. São Paulo: Pearson Prentice Hall.

Prensky, M. (2012) Aprendizagem baseada em jogos digitais. Tradução Eric Yamagute. São Paulo: Senac.

Savi, R. (2011) Avaliação de jogos voltados para a disseminação de conhecimentos. Tese. UFSC, Florianópolis.

Savi, R.; Ulbricht, V. R. (2008) Jogos digitais educacionais: benefícios e desafios. In: Renote: Revista novas tecnologias na educação, v. 6, n. 1 .

Tarouco, L. M. (2004) et al. Jogos educacionais. In: Renote: Revista novas tecnologias na educação. Porto Alegre.

Wangenheim, C., Kochanski, D.; Savi, R. (2009) Revisão Sistemática sobre Avaliação de Jogos voltados para Aprendizagem de Engenharia de Software no Brasil. In: XXIII SBIE, Rio de Janeiro. 